\title{
Proposta de melhoria para aumento de produtividade em um centro de usinagem
}

\author{
Ygor Geann dos Santos Leite Especialista em Engenharia da Qualidade e Seis Sigma. Faculdade Metropolitana de Manaus \\ (Fametro) - Brasil. ygor.geann.leite@gmail.com \\ Walkiria Batista Mikilis Leite Especialista em Engenharia da Qualidade e Seis Sigma. Faculdade Metropolita de Manaus \\ (Fametro) - Brasil.walkiriableite@gmail.com \\ Adriana Carvalho da Silva Especialista em Engenharia da Qualidade e Seis Sigma. Centro Universitário do Norte (Uninorte) - \\ Brasil.adrianacarvalhosv@gmail.com \\ Blenda Nunes da Silva Especialista em Engenharia da Qualidade e Seis Sigma. Centro Universitário do Norte (Uninorte) - \\ Brasil.eng.blendanunes@gmail.com \\ Luciano Izidoro Velho Especialista em Engenharia da Qualidade e Seis Sigma. Centro Universitário do Norte (Uninorte) - \\ Brasil. Iulukika02@gmail.com
}

\section{RESUMO}

Originalmente, os centros de usinagem surgem como um verdadeiro marco na história da metal-mecânica, reduzindo a minutos um trabalho que manualmente, levaria de horas até meses, correndo risco de no final de todo esse processo, a peça lapidada sair fora dos padrões especificados, de maneira que sua utilidade, não cabe mais àquilo que tanto foi planejada e moldada. Nesse sentido, o novo conceito de utilização das técnicas da usinagem é mais preciso, com chances mínimas de erros, porém, assim como no modelo artesanal, os erros existem podendo ser ainda mais agravantes com perdas imensuráveis de produção. Assim como qualquer máquina específica, os centros de usinagem necessitam de parâmetros e manutenção especial, do contrário, sua qualidade produtiva tende a declinar causando diretamente redução expressiva do potencial de produção e eminente geração refugos e demais desperdícios de matéria-prima. Dessa maneira, o artigo apresentará uma proposta de melhoria, em função de determinado centro de usinagem que vem apresentando queda de produção ao longo dos últimos seis meses. Os estudos, inicialmente, concentrarão esforços para identificação da causa raiz por meio da metodologia DMAIC e, posteriormente, apresentação de um projeto estruturado e eficiente.

Palavras-chave: Produtividade. Usinagem. Processo. Melhoria.

\section{Proposal for improvement to increase productivity in a machining center}

\begin{abstract}
Originally, the machining centers emerge as a true milestone in the history of mechanical metal, reducing a work that, manually, would take hours to months, running the risk of, at the end of the process, not having the facet of the cutting according to specified patterns and thus, not fitting the purpose it was designed and molded for. In this sense, the new concept of the use of machining techniques is more precise, with minimal chances of errors, but as in the craft production, the errors exist and can be even more aggravating leading to immeasurable losses of production. As with any specific machine, machining centers require parameters and special maintenance, otherwise their productive quality tends to decline causing expressive reduction of the production potential, eminent production of reject as well as waste of raw material. This way, the article will present a proposal for improvement, in the light of a certain machining center which has been presenting production decline over the last six months. The studies initially concentrate efforts to identify the root cause for such decline applying the DMAIC methodology, and will later, present a structured and efficient project.

Keywords: Productivity. Machining. Process. Improvement.
\end{abstract}




\section{INTRODUÇÃO}

Desde meados da revolução industrial, mudanças significativas aconteceram em processos produtivos, de maneira que cada vez mais as atividades ficaram automatizadas, necessitando de pouco contato humano para conclusão de determinado procedimento. Tais situações apenas enfatizam a busca pela produção ideal, com garantias de qualidade e precisão requeridas por determinado cliente ou processo. Entende-se por automatização, a utilização de mecanismos com funções repetitivas e precisas destinados a produção em massa, ou ainda aplicação de determinada função que não seja possível realização por um ser humano.

Segundo Horstmann (2008), massificar a produção de um produto, sempre foi o sonho de qualquer empresário da transformação durante séculos passados, porém, o homem em si possui limitações críticas, que de maneira direta, jamais conseguiria atingir o mesmo status de uma máquina, por mais que tentasse.

Contudo, o que antes poderia ser encarado como uma disputa de mercado, hoje a automação tratase do maior suporte e benefício industrial ao homem, que não necessita mais executar exaustivos movimentos e atividades, que antes the causava desgaste físico. Por mais que tais situações ainda sejam comuns nas indústrias do século XXI, é correto afirmar - por mais complicado que um processo possa parecer - que sempre existirão mecanismos de automação.

Identifica-se o centro de usinagem como uma das mais relevantes inovações tecnológicas voltadas para o meio industrial, proporcionando que a produção em massa de artefatos metálicos atenda à demandas de mercados variados. Outro ponto significativo dessas máquinas é a harmonia existente entre a precisão e agilidade na fabricação dos itens, reduzindo expressivamente as falhas no processo e, consequentemente, limitando as chances de perdas de matéria-prima o que resultaria em prejuízos financeiros.

De acordo com Rosário (2009), os centros de usinagem compõem as questões que a engenharia sempre teve como objetivo, trata-se de um equipamento com um nível de precisão tão avançado, chegando quase a substituir uma antiga linha de produção inteira, em apenas alguns traços. Tal afirmação se torna real, levando em consideração que alguns equipamentos podem comportar até 250 ferramentas de uma só vez.

Porém, todos esses benefícios, exigem um alto custo de investimento e adaptações, indo desde a exatidão da planicidade do solo onde será instalado às manutenções como: substituição de peças sobressalentes, atualizações de softwares. Todos esses fatores paralelamente trabalham em conjunto, apresentando excelentes níveis de rendimento e qualidade na precisão de sua produção. Do contrário, quando o centro de usinagem não recebe a devida atenção e cuidados, a tendência é que o nível de produtividade sofra queda expressiva e além disso, indícios da geração de refugo ficam mais evidentes.

A empresa pesquisada é fornecedora de embreagens para motos, atuando no polo industrial de Manaus há mais de vinte anos, sagrou-se como uma das mais competitivas do Brasil no ano de 2016. Possui 15 centros de usinagens, funcionando em dois turnos, porém dentre esses, encontra-se o equipamento listado como 006-2009, que apresenta quedas de produtividade contínuas nos últimos seis meses. Além disso, o desperdício de matéria-prima chegou a alarmantes $15 \%$.

Dessa maneira evidencia-se o problema: quais são os fatores que estão influenciando para o agravamento da queda de produção no centro de usinagem 006/2009? Como maneira de busca da causa raiz por meio de investigação eficiente, ao artigo contará com o suporte da metodologia DMAIC como base estrutural, e ainda de obras reconhecidas que servirão como suporte teórico para o desenvolvimento do trabalho.

\subsection{Objetivo geral}

Como objetivo geral, o artigo buscará apresentar a metodologia de investigação do DMAIC, como uma ferramenta consistente na pesquisa e identificação da causa raiz da problemática em evidencia. 


\title{
1.2 Objetivos específicos
}

Para objetivos específicos, pretende:

a) Utilização de conceitos geridos por meio da gestão da qualidade;

b) Aplicação coesa da metodologia DMAIC e todas as suas ramificações; e

c) Concentrar esforços para elaboração do plano de melhoria preciso e dentro das realidades da empresa.

\section{CENTROS DE USINAGEM}

Os centros de usinagem representam de maneira precisa a evolução da engenharia, voltada para as indústrias do ramo metalúrgico. São equipamentos que possuem eficiência específica para a produção de artefatos que possuem ligas metálicas como estrutura. Unindo com precisão os conceitos claros de automação e requisitos técnicos. As principais partes de um centro de usinagem são: Magazine, Eixo-árvore, Trocador, Acionamento, Servo motor, Cabeçote e Fuso.

\footnotetext{
Um centro de usinagem é uma máquina equipada com controle NC e dispositivo de troca automatizada de ferramentas, podendo gerenciar a execução a execução de várias operações em um só período (isto é, em um único processo interrupto). Os processos de perfuração e mandrilagem podem ser considerados como exemplos clássicos de centros de usinagem. Os centros de usinagem são utilizados na produção em série de pequeno e médio portes, e comprovam ser econômicos para componentes complexos de produção, mesmo para escalas pequenas de produção. (SCHEER, 1993, p. 46).
}

Desse modo, aponta-se que a relevância dos centros de usinas para a indústria, não está apenas na quantidade e no modelo produtivo, mas, também diretamente relacionado com a redução de custo que todo o processo exige.

Essas reduções, são referentes à geração de refugo de matéria-prima. Levando em consideração que os equipamentos de usinagem atuam diretamente naquilo do qual foram programados, utilizando ferramentas e agilidades distintas, as chances do surgimento de refugo são reduzidas consideravelmente, de modo que o aproveitamento real dos investimentos aplicados na produção, ficam igual com aquilo que foi programado ainda na fase de projetos. Para atingir a esses requisitos, estipula-se no início do processo de usinagem uma quantidade mínima de peças acabadas que deverão passar por determinados testes de medições, a fim de constatar que os demais itens produzidos para um lote distinto está devidamente atendendo aos padrões de solicitação.

\begin{abstract}
Em um sistema convencional de controle da qualidade, uma peça usinada em um centro de usinagem é removida e enviada par a máquina de medição por coordenada (MMC) para verificar sua precisão dimensional. O tempo despendido para o trabalho manual de montagem e inspeção de peças usinadas não agrega valor ao produto. Essas etapas são sujeitas a erros humanos. (RODRIGUES et al, 2015, p. 179).
\end{abstract}

Mesmo levando em consideração que todo o processo de fabricação é executado pelo equipamento, os parâmetros iniciais devem ser inseridos por meio do operador do centro, cujo este deverá seguir o roteiro pré-estabelecido para cada peça que será produzida. Assim, os erros humanos são comuns, logo, para evitar maiores problemas quanto a produção não conforme, executa-se a processo de acordo com os mencionados pelo autor.

Em algumas situações, visando redução de custo, os produtos a serem testados, não necessariamente precisam sair dos arredores do centro de usinagem, ou ser destinados a outros departamentos. Alguns equipamentos, possuem estrutura suficiente para execução desse tipo de atividade, in loco no processo de usinagem.

A fim de evitar o trabalho de levar a peça para a inspeção em uma máquina de medir coordenadas, há uma tendência de utilizar o próprio centro de usinagem que fabricou a peça para realizar as operações de inspeção por coordenadas. Nesse caso, o apalpador é fixado ao eixo-árvore da máquina CNC (o apalpador pode ficar no magazine da máquina, como outra ferramenta qualquer). (RODRIGUES et al, 2015, p. 185). 
Para garantir que determinado centro de usinagem esteja em pleno funcionamento, os procedimentos de manutenção devem ocorrer rigorosamente, buscando identificar e corrigir possíveis imperfeições que diretamente podem prejudicar o andamento eficiente da produção. De acordo com Scheer (1993), em máquinas de qualquer natureza, a manutenção correta, significa garantia de vida útil com total atendimento aos requisitos solicitados.

\section{GESTÃO DA QUALIDADE}

A qualidade em si abarca diferentes definições, devido a abrangência do termo por ser um conceito utilizado diariamente por industrias e consumidores, frisa em produtos de qualidade.

Segundo Silva (2014), após a Segunda Guerra Mundial surgem dois teóricos da qualidade na época, Willian Edward Deming e Joseph Juran, onde ambos contribuíram significativamente para o grande marco na criação da Gestão da Qualidade, bem como suas aplicações aos procedimentos dos mais variados tipos de organizações. Deming (1986 apud Silva 2014), apresenta a teoria que a qualidade é quaisquer circunstâncias que os clientes precisem por aplicações estáticas e de melhoria contínua, já Juran (1951 apud Silva 2014), define que qualidade é uma adequação ao uso.

Ao contar na Revolução Industrial extrai um novo conceito na produção na fase de larga escala, onde veio com intuito de substituir a customização. Em sequência, na era taylorista como novidade na qualidade e inspetor, compreende que as atribuições e responsabilidade da qualidade no produto acabado, exibindo os produtos defeituosos e/a descartados (FABRIS, 2014).

Segundo Silva (2014), com o decorrer do processo evolucionário do século XX, tende aos marcos apresentado quatro fases: I. Inspeção do Produto; II. Controle de Processo; III. Sistemas de Garantia da Qualidade; e IV. Gestão da Qualidade Total, diante desses requisitos resulta a origem da ISO 9000, onde vem sendo adotada por grandes organizações em busca de agregar a competitividade.

De acordo com Fabris (2014), as ferramentas da qualidade clássicas buscam auxiliar e tem como base de apoio em tomada de decisões, em busca de melhorar uma situação, e solucionar problema que está acontecendo no momento e posteriormente. Deste modo, seu objetivo é de prever a causa do problema, mensurar e coibir o aparecimento dos problemas defeituosos. Por tanto, as ferramentas básicas da qualidade dispõem das seguintes ferramentas dentre elas estão: estratificação, folhas de verificação, análise de Pareto, diagramas de Ishikawa (espinha de peixe ou diagrama de causa-efeito), histogramas, diagramas de dispersão e gráficos de controle.

Para Silva et al. (2013), além de existirem diversas ferramentas da qualidade vale ainda destacar o $5 \mathrm{~W} 2 \mathrm{H}$, tem-se o papel de organizar o plano de ação, planejamento e até mesmo de busca de resultados. Foi criada na indústria automobilística no Japão, tendo como ferramenta auxiliar na utilização da Ferramenta do PDCA por dar suporte no planejamento. O autor ainda descreve que por consistir no plano de ação especificando necessidade a ser desenvolvida de maneira mais clara possível.

Com os avanços dos estudos aplicados aos Seis Sigma, as ferramentas da qualidade passaram a ter a mesma significância a metodologia DMAIC, que assim como o PDCA, busca identificação das causas que levaram a ocorrência de determinadas problemáticas.

\section{METODOLOGIA DMAIC}

Por estar presente na abordagem do Seis Sigma, a ferramenta visa a aperfeiçoar o processo por melhorias e possibilita a capacitação de colaboradores por treinamentos, técnicas estatísticas, através de lógica matemática, assim facilita a utilização da metodologia DMAIC, facilitando os ganhos, tanto em qualidade quanto de custos.

Segundo Ramos et al. (2014), o ciclo do DMAIC está presente nas ferramentas do Seis Sigma, tem como base da ISO 9000 e pelo Total Quality Management - TQM, e por ser uma ferramenta muito parecida com o PDCA, tende a mensurar melhorias de formas eficientes e eficazes. Por tanto, a Metodologia DMAIC tende a solucionar problemas por ter conjuntos ordenados, classificando pelas seguintes etapas, conforme a Figura 1. 
Figura 1 - Diagrama DMAIC

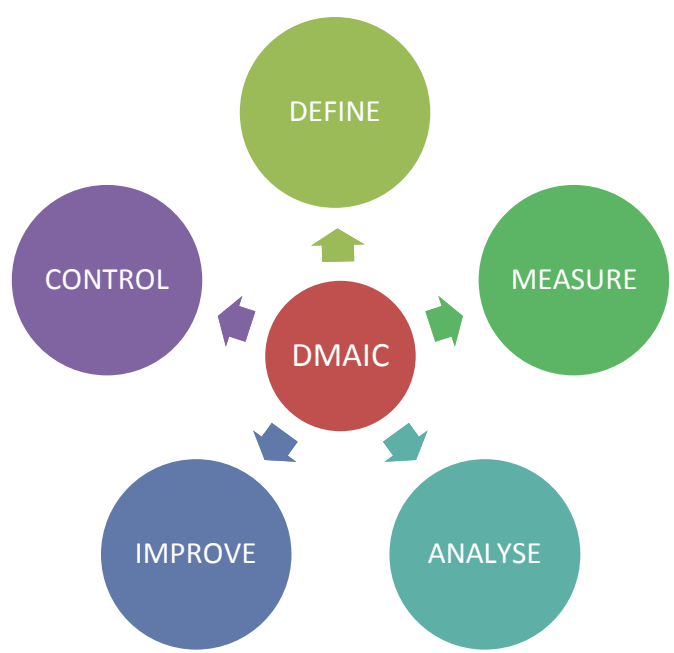

Fonte: Elaborado pelos autores (2017).

Conforme a figura 1, obtemos a divisão em cinco fases, segundo Andrietta (2007 apud RAMOS et al, 2014) classifica em:

Define (Definir): Análise das expectativas do cliente em que são identificados as etapas e os produtos do processo, ou seja, define de forma precisa o escopo do projeto.

Measure (Medição): Mensurar para obter informações a fim de executar o mapa de processo e elaborar a matriz de causa e efeito, determinando o foco do problema.

Analyse (Análise): Identificar o desempenho em relação à meta estabelecida, detectando os possíveis gargalos do processo. Fase necessária ao uso de software estatístico para a realização de cálculos e gráficos que permitem conhecer as não conformidades dos processos e as suas variações.

Improve (Melhoria): Desenvolver soluções para intervir no processo reduzindo significativamente os níveis de defeitos.

Control (Controlar): Controlar e monitorar o processo para manter os resultados obtidos.

Uma das maiores contribuições para a efetivação máxima da metodologia DMAIC, é o uso de dados estatístico para aprimoramento de um plano de melhoria consistente, que além de estar de acordo com a realidade da organização, atuará exatamente naquilo ao qual foi proposto.

As ferramentas estatísticas usadas nos cinco passos do DMAIC ajudam a identificar, quantificar e eliminar a causa raiz do problema, sustentando a melhoria do desempenho da linha de produção, aumentando a satisfação do cliente e melhorando significativamente a rentabilidade em todos os setores de muitas organizações do mundo todo (PRASHAR, 2014 apud ESCANFERLA, 2014).

Para atendimento a esses requisitos, o DMAIC, possui por padrão, relação direta com as ferramentas da qualidade. Levando em consideração que essas são condições gerenciais para a apresentação da problemática devidamente identificada e mensurada, parte dos objetivos principais da melhoria contínua são atendidos.

Para complementar a problemática da pesquisa, se faz necessário desenvolver alguns objetivos específicos, tais como: aplicar as ferramentas de gestão da qualidade, 5W2H, Diagrama de Causa e Efeito, técnica dos " 5 porquês", fluxograma e matriz de priorização, nas etapas do método DMAIC; identificar as possíveis existências de variações que possam ocorrer e afetar a qualidade do produto final e avaliar quais os benefícios proporcionados à qualidade dos produtos da empresa (HOLANDA, 2013).

Importar frisar que plano de ação elaborado por meio das técnicas do DMAIC, devem estar estruturadas principalmente com foco no problema evidenciado. Consequentemente, este apresentará outras ramificações que não foram apresentadas ao longo das demais etapas. Parte esses casos, recomenda-se que o planejamento não seja totalmente definido, e retorno as análises dos demais dados apresentados, buscando identificar as possíveis informações que passarão despercebidas. No entanto, os líderes mencionados, devem continuamente ser informados dessas reincidências. 
É identificado no plano de controle que, para cada ação, deve existir um responsável, o supervisor, e este deve verificar semanalmente as planilhas de inspeção de produtos acabados para que seja analisada a situação dos mesmos. Existindo frequência de defeitos encontrados internamente, o inspetor de qualidade deve promover um treinamento mensal para ensinar e apresentar técnicas corretas de utilização das máquinas. A figura do líder de produção deve dividir os colaboradores em grupos para a realização de reunião e palestras, orientando-os para a retirada do material defeituoso, evidenciando as consequências desagradáveis e prejudiciais, caso esta ação venha a ser omitida (HOLANDA, 2013).

\section{ESTUDO DE CASO}

A empresa pesquisada é a única do Polo Industrial de Manaus especializada na produção de embreagens para veículos de duas e quatro rodas. Tendo os fabricantes de motos japonesas como os maiores clientes, apresenta um alto poder de produção, principalmente para motocicletas entre 125 e 250 cilindradas.

O setor de usinagem dispõe de 15 centros, onde destes, 12 funcionam em dois turnos, e os demais, em caráter de rodízio para atendimento imediato de altos índices de produção ou para preenchimento de estoque de segurança. A tabela 1, demostra a quantidade de produtiva em condições normais.

Tabela 1 - Capacidade produtiva

\begin{tabular}{cc}
\hline CENTRO DE USINAGEM & POTENCIAL DE PRODUÇÃO (Peças/H) \\
\hline $001 / 2002$ & 90 \\
$002 / 2002$ & 90 \\
$003 / 2004$ & 110 \\
$004 / 2006$ & 110 \\
$005 / 2006$ & 110 \\
$006 / 2009$ & 125 \\
$007 / 2009$ & 125 \\
$008 / 2009$ & 125 \\
$009 / 2010$ & 140 \\
$010 / 2010$ & 140 \\
$011 / 2011$ & 160 \\
$012 / 2011$ & 160 \\
$013 / 2012$ & 200 \\
$014 / 2012$ & 200 \\
$015 / 2012$ & 200 \\
\hline
\end{tabular}

Fonte: Elaborado pelos autores (2017).

O potencial de produção, está diretamente relacionado com as tecnologias utilizadas na máquina, sendo este o ponto diferencial entre cada centro. Cada máquina possui em sua codificação, o ano em que entrou em operação, desse modo, o gestor do processo consegue realizar comparativos, entre o total solicitado e a realidade operacional de cada equipamento. Outro ponto ainda em relação a quantidade de produção, quanto mais tempo de uso o centro de usinagem tiver, a tendência é que a exigência produtiva sofra uma redução, de acordo com tabela padrão de cada fabricante. Os equipamentos 013, 014 e 015/2016, foram adquiridos recentemente, onde estes apresentam tecnologia superior aos demais, por isso, a utilização destes é estratégica. A aquisição desses faz parte de um projeto da empresa do qual a mesma almeja a substituição de todos os equipamentos com mais de 10 anos de uso.

Quase todos os equipamentos apresentam condições produtivas bem próximas ao seu potencial de produção original, de maneira que as poucas vezes que ficam abaixo do esperado, detecta-se que influência direta de fatores externos como queda de energia, para o não atendimento das metas. Porém, a máquina 
006/2009 tem apresentado sequentes imprecisões na sua programação de produção, apresentando queda expressiva na produtividade. A afirmação poderá ser melhor visualizada, por meio da tabela 2, em um levantamento de dados referentes à quantidade produtiva nos primeiros seis meses do ano de 2017.

Tabela 2 - Produtividade mensal 006/2009

\begin{tabular}{ccc}
\hline MÊS & PRODUÇÃO PROGRAMADA & PRODUÇÃO REAL \\
\hline Janeiro & 1600 & 1100 \\
Fevereiro & 1650 & 1250 \\
Março & 1550 & 1100 \\
Abril & 1700 & 1280 \\
Maio & 1600 & 1245 \\
Junho & 1650 & 1198 \\
\hline TOTAL & 9750 & 7173 \\
\hline & Fonte: Elaborado pelos autores (2017).
\end{tabular}

Dessa maneira, essa redução expressiva de produtividade ao centro de usinagem 006/2009, passa a ser a problemática a ser resolvida, em caráter de urgência, levando em consideração que os custos de produção continuam sendo aplicados na mesma.

\section{PROPOSTA DE MELHORIA}

Como aplicação de técnicas investigativas, de modo a conseguir identificar a causa da problemática em evidência, o artigo se apoiará nas metodologias aprimoradas por meio do DMAIC. Essa ferramenta de gestão foi escolhida devido à complexidade da situação, não apenas em relação ao equipamento em si, mas principalmente, a possíveis insatisfações com os clientes finais devido a atrasos na entrega, e ainda, algumas imperfeições apontadas no lote, onde em um rastreio com a codificação apresentada, afirmou-se que os produtos fora da especificação foram produzidos no equipamento em questão.

\subsection{Define}

As informações de definição do problema, foram evidenciadas na tabela 02, com a apresentação dos dados referentes as informações de programação de produção, com os dados reais do processo elaborado no centro de usinagem 006/2009. Com essa definição conclusiva, buscando melhor identificação das principais atividades executadas, elaborou-se o mapa de processo SIPOC, para identificação dos elementos que diretamente estão relacionados ao problema em evidência. Levando em consideração que as atividades de usinagem ocorrem após procedimentos de fundição de ligas de alumínio, para dar formas iniciais do platô e cubo de embreagem.

Quadro 1 - Mapa SIPOC

\begin{tabular}{|c||c|c|c|c|}
\hline \multicolumn{2}{|c|}{ MAPA DO PROCESSO-SIPOC } \\
\hline Suppliers & Inputs & Process & Outputs \\
\cline { 1 - 2 } $\begin{array}{c}\text { Empresa fornecedora de ligas de } \\
\text { alumínio }\end{array}$ & Entradas & Processo & $\begin{array}{c}\text { Secebimento do pedido ou } \\
\text { programação de produção }\end{array}$ & $\begin{array}{c}\text { Platô concluído, } \\
\text { direcionado ao setor de } \\
\text { montagem }\end{array}$ \\
\hline
\end{tabular}




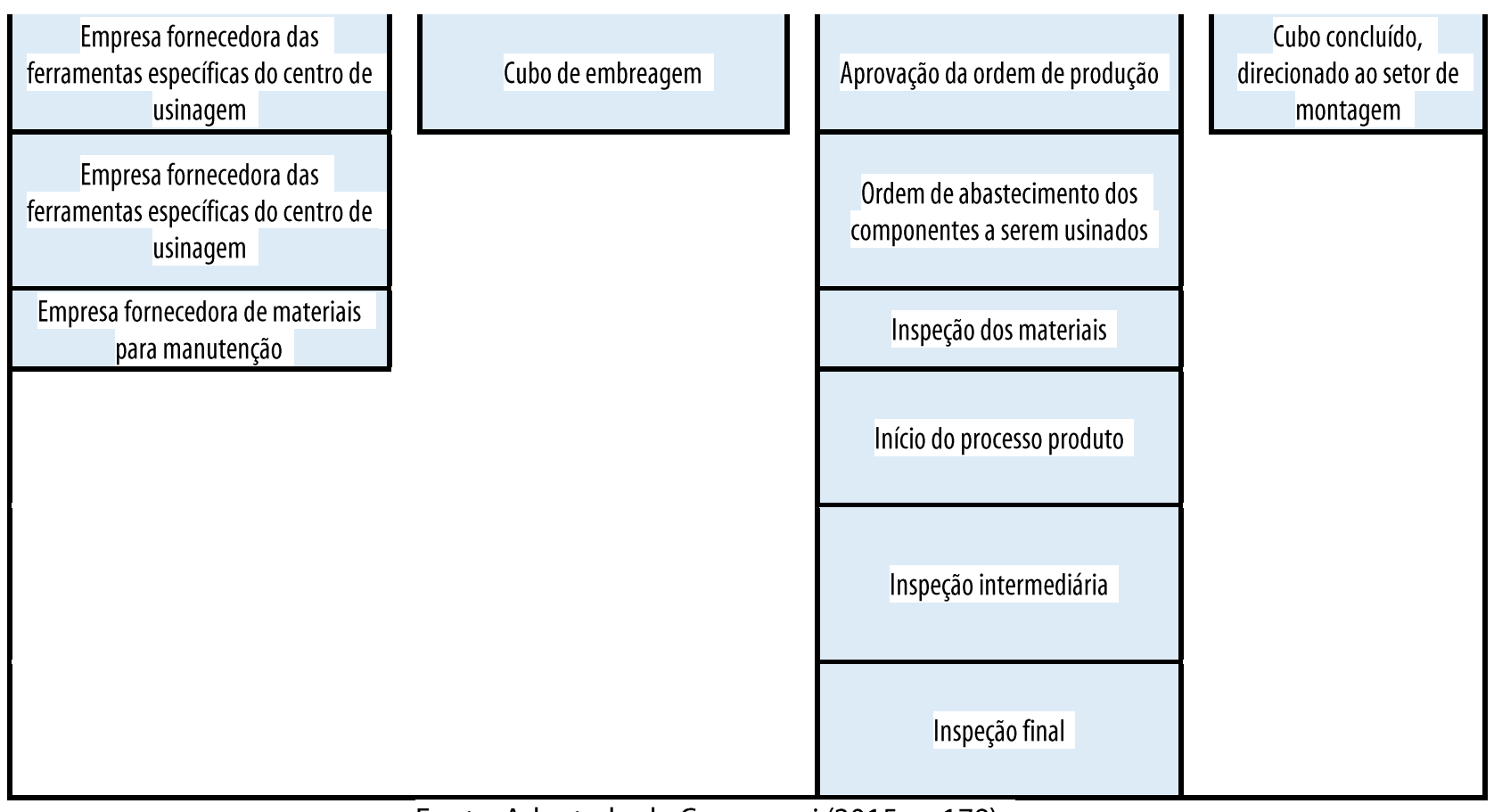

Fonte: Adaptado de Cremonezi (2015, p. 178).

Pelo mapa de processo identifica-se que em condições normais, após a conclusão do processo de usinagem, existem duas inspeções: secundária e final. A inspeção secundária, ocorre pelo próprio operador da máquina, considerando a quantidade de cinco itens por lote. Onde em seguida, as mesmas inspeções ocorrem por colaboradores do setor da qualidade, que atestam os parâmetros do produto, direcionando os mesmos para o setor de montagem. Para o equipamento 006/2009, a maioria dos produtos são reprovados mesmo na inspeção intermediária, causando atrasados consistentes na produção de um lote.

Para esses casos, mesmo gerando inúmeros indícios de refugos, esses são reaproveitados retornando a característica de matéria-prima no setor de fundição, porém, existe uma preocupação que com a incidência dessa rotina, a qualidade final do produto com base em matéria-prima retrabalhada, seja abaixo do especificado.

\subsection{Measure}

Mensurar o problema em questão terá como apoio inicial os dados da tabela 2, buscando identificar qual é o percentual de redução na produção. Essas informações necessárias, para apresentação da mesma aos gestores da empresa, de agregar valor à implantação das ações de melhoria.

Tabela 3 - Percentual de redução

\begin{tabular}{lccc}
\hline \multicolumn{1}{c}{ MÊS } & $\begin{array}{c}\text { PRODUÇÃO } \\
\text { PROGRAMADA }\end{array}$ & PRODUÇÃO REAL & \% DE REDUÇÃo \\
\hline Janeiro & 1600 & 1100 & $31,25 \%$ \\
Fevereiro & 1650 & 1250 & $24,24 \%$ \\
Março & 1550 & 1100 & $29,03 \%$ \\
Abril & 1700 & 1280 & $24,71 \%$ \\
Maio & 1600 & 1245 & $22,19 \%$ \\
Junho & 1650 & 1198 & $27,39 \%$ \\
\hline TOTAL & 9750 & 7173 \\
\hline \multicolumn{4}{c}{}
\end{tabular}

Fonte: Elaborado pelos autores (2017). 
Identificou-se ainda que para os produtos reprovados na inspeção secundária, existem cinco ocorrências mais comuns, no qual essas, serão apresentadas na tabela 4.

Tabela 4 - Ocorrências

\begin{tabular}{lcc}
\hline \multicolumn{1}{c}{ OCORRÊNCIAS } & QUANTIDADE & OBSERVAÇÕES \\
\hline Excesso de rebarba nas bordas & 780 & Causas surgem no platô e cubo \\
Planicidade fora do especificado & 937 & Causas surgem no platô e cubo \\
Diâmetro para parafusos fora do especificado & 698 & Causas surgem no platô e cubo \\
Profundidade do diâmetro fora do especificado & 871 & Causas surgem no platô e cubo \\
Altura das torres fora do especificado & 493 & Somente no platô \\
\hline TOTAL & 3779 & \\
\hline
\end{tabular}

Fonte: Elaborado pelos autores (2017).

\subsection{Analyse}

As informações referentes a tabela 03, foram, convertidas em um gráfico de Pareto, como maneira de melhor visualização, bem como um modelo eficiente de indicador de desempenho.

\section{Figura 1 - Gráfico de Pareto}

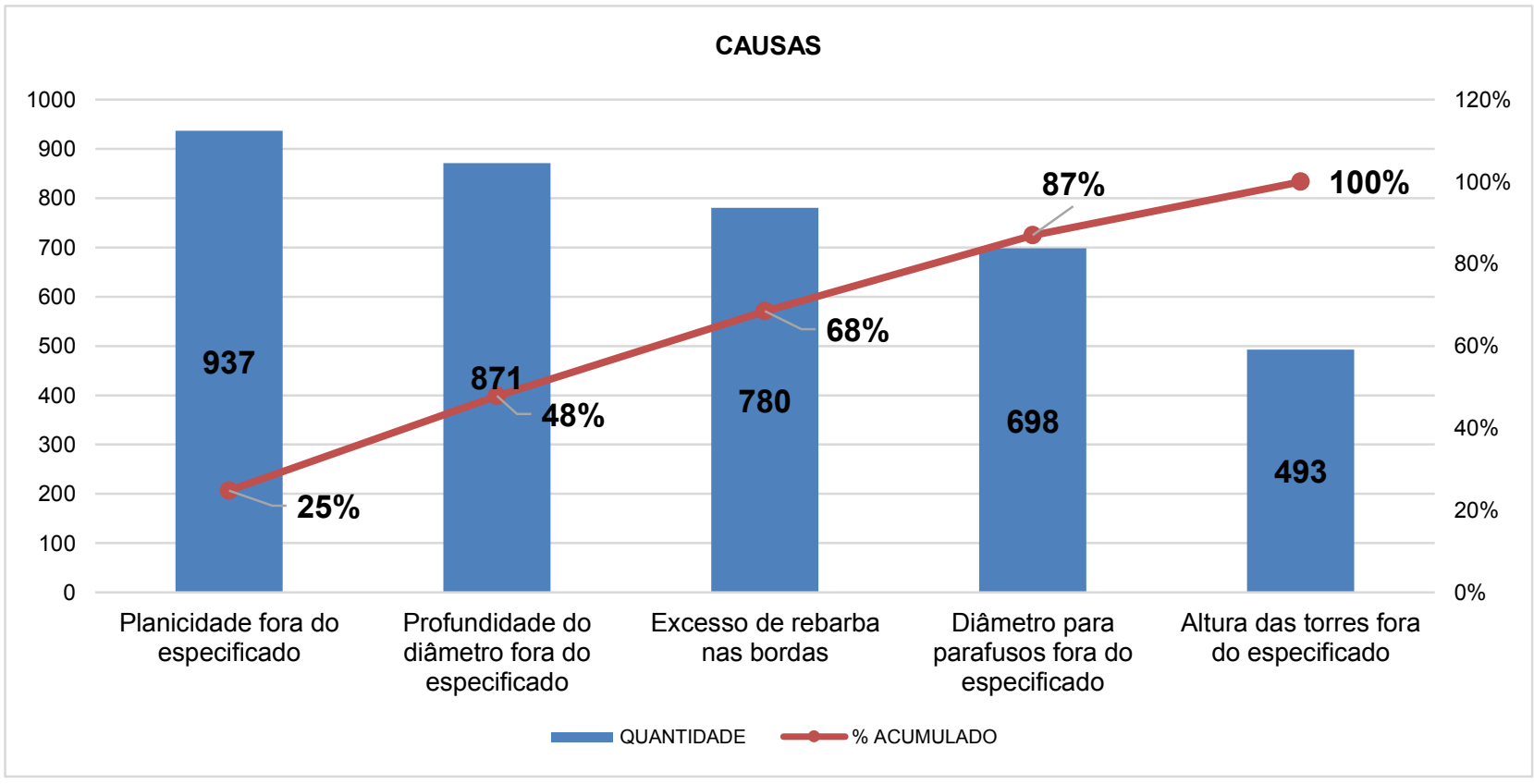

Fonte: Adaptado de Lucinda (2010, p. 78).

Buscando entender a fundo como as ocorrências mencionadas surgem, elaborou-se o Quadro 2 elencando por meio dos dados do fabricante do equipamento, quais os possíveis fatores que impactam nos eventos apontados. 
Quadro 2 - Ocorrências x Motivos

\begin{tabular}{|l|l|}
\hline \multicolumn{1}{|c|}{ OCORRÊNCIA } & \multicolumn{1}{c|}{ MOTIVO } \\
\hline Planicidade fora do especificado & Ferramenta de nível não calibrada \\
\hline Profundidade do diâmetro fora do especificado & Ferramenta de profundidade não ajustada \\
\hline Excesso de rebarba nas bordas & Ferramenta removedora de rebarbas não calibrada \\
\hline Diâmetro para parafusos fora do especificado & Parâmetro de diâmetro não ajustado \\
\hline Altura das torres fora do especificado & Parâmetro de altura não ajustado \\
\hline
\end{tabular}

Fonte: Elaborado pelos autores (2017).

Apesar dos motivos potencialmente estarem relacionados com a com os parâmetros de produção e as ferramentas em si, evidencia-se que essas duas condições já foram verificadas anteriormente, de maneira que constantemente existe a necessidade de reajuste, situação que não é característica normal de um centro de usinagem. De outro lado, o fabricante informou que em condições críticas a ajustes de manutenção, o comportamento do equipamento tende a apresentar algumas anomalias, das quais, perdas de parâmetros e utilização ineficiente das ferramentas.

\subsection{Improve}

Com essas informações, buscou-se elaborar o plano de ação tendo como base os dados de registros de manutenção, cujas as execuções preventivas realizadas no mês de dezembro/2016, o item sobressalente bomba de alta pressão, tinha sido substituído por outro não especificado pelo fabricante. Como esse item foi único substituído nesse período, passou a ser o tema central da proposta de melhoria (Quadro 3).

Quadro 3 - 5W2H

\begin{tabular}{|c|c|c|c|c|c|c|c|}
\hline \multicolumn{3}{|c|}{ Projeto } & \multicolumn{5}{|c|}{ Aumento de produtividade no equipamento 006/2009 } \\
\hline $\begin{array}{l}\text { Proble- } \\
\text { mas }\end{array}$ & $\begin{array}{c}\text { O que será } \\
\text { feito? }\end{array}$ & Quem fará? & Quando? & Onde? & Por que? & Como? & $\begin{array}{c}\text { Quanto } \\
\text { custa? }\end{array}$ \\
\hline $\begin{array}{l}\text { Profundida } \\
\text { de do } \\
\text { diâmetro } \\
\text { fora do } \\
\text { especifica- } \\
\text { do }\end{array}$ & $\begin{array}{l}\text { Substituir a } \\
\text { bomba de } \\
\text { alta de } \\
\text { pressão } \\
\text { instalada, } \\
\text { por outra } \\
\text { recomenda } \\
\text { da pelo } \\
\text { fabricante }\end{array}$ & $\begin{array}{c}\text { Gestor de } \\
\text { manutenção/ } \\
\text { compras }\end{array}$ & $\begin{array}{c}\text { Prazo } \\
\text { final } \\
\text { dez/2017 }\end{array}$ & $\begin{array}{c}\text { No } \\
\text { fornecedor } \\
\text { oficial de } \\
\text { peças } \\
\text { sobressa- } \\
\text { lentes }\end{array}$ & $\begin{array}{l}\text { Identificou-se } \\
\text { que no final do } \\
\text { ano de } 2016, \text { a } \\
\text { bomba de alta } \\
\text { pressão do } \\
\text { equipamento } \\
\text { 006/2009, } \\
\text { necessitou de } \\
\text { troca pelo } \\
\text { desgaste normal. } \\
\text { Como não } \\
\text { conseguiu-se } \\
\text { adquirir de } \\
\text { acordo com as } \\
\text { recomendações } \\
\text { do fabricante, foi }\end{array}$ & $\begin{array}{c}\text { O } \\
\text { fornecedor } \\
\text { oficial de } \\
\text { sobressa- } \\
\text { lentes, } \\
\text { informou } \\
\text { que a } \\
\text { mesma } \\
\text { está } \\
\text { disponível } \\
\text { para } \\
\text { aquisição }\end{array}$ & $\mathrm{R} \$ 4.600,00$ \\
\hline
\end{tabular}




\begin{tabular}{|c|c|c|c|c|c|c|c|}
\hline $\begin{array}{l}\text { Excesso de } \\
\text { rebarba nas } \\
\text { bordas }\end{array}$ & & & & & $\begin{array}{c}\text { comprada de } \\
\text { uma marca } \\
\text { alternativa, que } \\
\text { causa } \\
\text { trepidações } \\
\text { acima do } \\
\text { especificado, } \\
\text { levando o } \\
\text { equipamento a } \\
\text { perder seus } \\
\text { parâmetros }\end{array}$ & & \\
\hline $\begin{array}{l}\text { Diâmetro } \\
\text { para } \\
\text { parafusos } \\
\text { fora do } \\
\text { especifica- } \\
\text { do }\end{array}$ & \multirow{2}{*}{$\begin{array}{c}\text { Adquirir } 6 \\
\text { novas } \\
\text { ferramentas } \\
\text { de } \\
\text { padroniza- } \\
\text { ção de } \\
\text { diâmetro e } \\
\text { altura }\end{array}$} & \multirow{2}{*}{$\begin{array}{l}\text { Gestor de } \\
\text { manutenção/ } \\
\text { compras }\end{array}$} & \multirow{2}{*}{$\begin{array}{c}\text { Prazo } \\
\text { final } \\
\text { dez/2017 }\end{array}$} & \multirow{2}{*}{$\begin{array}{l}\text { No } \\
\text { fornecedor } \\
\text { oficial de } \\
\text { peças } \\
\text { sobressa- } \\
\text { lentes }\end{array}$} & \multirow{2}{*}{$\begin{array}{c}\text { Notou-se } \\
\text { pequeno } \\
\text { empeno na } \\
\text { ponta das } \\
\text { ferramentas } \\
\text { atuais, condição } \\
\text { que diretamente } \\
\text { causa precisão } \\
\text { em relação aos } \\
\text { parâmetros } \\
\text { especificados }\end{array}$} & \multirow{2}{*}{$\begin{array}{l}\text { Adquirir } \\
\text { junto ao } \\
\text { fornecedor } \\
\text { oficial }\end{array}$} & $\begin{array}{l}\text { - Valor } \\
\text { unitário } \\
\text { R\$619,00 }\end{array}$ \\
\hline $\begin{array}{l}\text { Altura das } \\
\text { torres fora } \\
\text { do } \\
\text { especifica- } \\
\text { do }\end{array}$ & & & & & & & $\begin{array}{l}\text { - Valor } \\
\text { total } \\
\mathrm{R} \$ 3.714,00\end{array}$ \\
\hline
\end{tabular}

Fonte: Adaptado de Lucinda (2010, p. 127).

\subsection{Control}

A bomba de alta pressão exerce a função crucial de quebrar os cavacos e liberar as ferramentas aplicadas, das fagulhas de metal, com isso, centro de usinagem atua de maneira livre e limpa, evitando que fatores adversos venham a comprometer a qualidade final dos itens que estão sendo produzidos.

Mesmo com a aquisição e instalação de uma bomba não recomendada pelo fabricante, o equipamento não acusou nenhum tipo de falha por meio dos seus alarmes de advertências, porém, identificou-se posteriormente excesso de vibrações no centro de usinagem. Essa anomalia foi identificada no momento em que foram realizados testes tendo como base os equipamentos semelhantes que estavam em total concordância com as recomendações do fabricante. As vibrações apresentadas levavam o equipamento a atuar de maneira irregular inibindo funções específicas de cada ferramenta aplicada. Esse fator somado aos constantes procedimentos de produção, a curto prazo, comprometeria completamente o jogo de ferramentas e demais outros componentes do centro de usinagem, de modo que a tendência a médio prazo seria tornar o equipamento obsoleto.

Contudo, para evitar que esse tipo de situação se repita ao longo das manutenções solicitou-se ao fornecedor, lista atualizada dos componentes sobressalentes recomendados pelo fabricante. De outro lado, esta lista foi encaminhada ao setor de compras, no qual, nenhum outro item ou marca, além do especificado, poderá ser adquirido, podendo apresentar penalidades aos envolvidos que não seguirem esse procedimento adotado. 


\section{CONCLUSÃO}

Cada máquina possui uma particularidade tão específica, que mais que terceiros tentem de alguma maneirar burlar essa condição característica, a tendência é que prejuízos maiores sejam apresentados. Por mais que momentaneamente ações aplicadas aparentam ter surtido o efeito positivo, algo não percebido pode ocasionar situação ainda mais prejudicial, muitas vezes, colocando em risco não apenas o processo produtivo, mas a vida de pessoas.

Os eventos apresentados no artigo confirmam essa afirmação, por mais que as causas ainda estivessem relacionadas, somente a perdas expressivas de produção, existe uma tendência de que os fatores poderiam se desenvolver, a ponto de causar lesões no operador devido as condições de segurança do equipamento, possivelmente serem afetadas devido as vibrações em excesso.

Já apresentando um estado de criticidade bastante considerável em relação ao andamento do planejamento da produção, o centro de usinagem 006/2009 é consequência de uma atitude momentânea para simples resolução imediata do problema, ou seja, apenas pela necessidade de substituir determinado componente, sem pensar nas sequelas que essa ação poderia apresentar.

Os resultados negativos deixaram marcas expressivas ao setor, onde por vezes, colaboradores tiveram que ampliar suas atividades diárias para tentar garantir a entrega de um lote específico, isso gera custos não programados além de expor o trabalhador a condição excessiva de trabalho, podendo ainda a empresa ser penalizada por questões trabalhistas.

O artigo tornou-se eficiente em suas ações, principalmente com o cuidado aos métodos de pesquisas, indo em busca do que realmente poderia ser identificado como a causa raiz da problemática evidenciada. No qual, diversos levantamentos foram elaborados, bem com a apreciação de documentação específica pertinente as atividades do setor de usinagem e manutenção.

Por questões de segrego industrial, a empresa estudada não permitiu a divulgação de maiores informações das ações realizadas, porém, estudos realizados em conjunto com a engenharia e manutenção, confirmaram que a causa raiz do problema foi diagnosticada de maneira precisa, necessitando apenas da chegada da nova bomba de alta pressão para conclusão efetiva e realização de demais procedimentos padrões.

\section{REFERÊNCIAS}

CREMONEZI, Graziela. Administração Básica. Campo Grande: Life Editora, 2015.

ESCANFERLA, Davi. Projeto DMAIC com ferramentas seis sigma para redução de sucata em uma multinacional do ramo de acessórios automobilísticos. 2014. 64f. Trabalho de Conclusão de Curso (Graduação em Engenharia Mecânica) - Faculdade de Engenharia, Universidade Estadual Paulista, Guaratinguetá, 2014. Disponível em:<https://repositorio.unesp.br/bitstream/handle/11449/124318/000822461.pdf?sequence=1>. Acesso em: 10 out. 2017.

FABRIS, Caroline Bertinatto. Aplicação das Ferramentas da Qualidade em um processo produtivo em uma indústria de ração. 2014. 74f. Trabalho de Conclusão de Curso (Graduação em Engenharia da Produção) - Universidade Tecnológica Federal do Paraná, Medianeira, 2014. Disponível em:< http://repositorio.roca.utfpr.edu.br/jspui/bitstream/1/4327/1/MD_COENP_TCC_2014_2_03.pdf >. Acesso em: 10 out. 2017.

HOLANDA, Lucyanno Moreira Cardoso. Proposta de aplicação do método DMAIC para melhoria da qualidade dos produtos numa indústria de calçados em Alagoa Nova-PB. [2013]. Disponível em:< http://revista.feb.unesp.br/index.php/gepros/article/viewFile/974/517>. Acesso em: 10 out. 2017.

HORSTMANN, Matheus. Projeto e Implantação de uma Linha Produtiva. [2008]. Disponível em:< http://siaibib01.univali.br/pdf/Matheus\%20Horstmann.pdf>. Acesso em: 10 out. 2017. 
LUCINDA, Marco Antônio. Qualidade: Fundamentos e Práticas. São Paulo: Brasport, 2010.

RAMOS, Fabrícia Vieira et al. Gestão de projetos através do DMAIC. [2014]. Disponível em:<http://www.abepro.org.br/biblioteca/enegep2014_TN_STO_202_145_25319.pdf>.Acesso em: 10 out. 2017.

RODRIGUES, Alexandre Roger et al. Desenho Técnico Mecânico Projeto e Fabricação no

Desenvolvimento de Produtos Industriais. Rio de Janeiro: Elsevier: 2015.

ROSÁRIO, João Maurício. Automação Industrial. São Paulo: Baraúnas: 2009.

SCHEER, August Wihelm. CIM: Evoluindo para Fábrica do Futuro. Rio de Janeiro: Qualitymark:1993.

SILVA, David Becker. Implantação de um sistema de gestão da qualidade em uma empresa do setor metal mecânico. [2014]. Disponível

em:<http://www.fahor.com.br/publicacoes/TFC/EngPro/2014/David_Becker_da_Silva.pdf>.Acesso em: 10 out. 2017.

SILVA, Alison et al. Gestão da qualidade: aplicação da ferramenta 5 w2h como plano de ação para projeto de abertura de uma empresa. [2013]. Disponível em:<http://www.fahor.com.br/publicacoes/sief/2013/gestao_de_qualidade.pdf>. Acesso em: 10 out. 2017. 